\title{
Volatile compound profiling of Turkish Divle Cave cheese during production and ripening
}

\author{
S. Ozturkoglu-Budak, ${ }^{\star}{ }^{1}$ A. Gursoy, ${ }^{*}$ D. P. Aykas, $\ddagger \S$ C. Koçak, ${ }^{\star}$ S. Dönmez,\# R. P. de Vries, $†$ and P. A. Bronll \\ *Department of Dairy Technology, Faculty of Agriculture, Ankara University, 06110 Ankara, Turkey \\ †Fungal Physiology, CBS-KNAW Fungal Biodiversity Centre \& Fungal Molecular Physiology, Utrecht University, 3584 Utrecht, the Netherlands \\ łDepartment of Food Science and Technology, The Ohio State University, 110 Parker Food Science and Technology Building, 2015 Fyffe Road, \\ Columbus 43210 \\ §Department of Food Engineering, Faculty of Engineering, Adnan Menderes University, 09100 Aydin, Turkey \\ \#Department of Food Engineering, Faculty of Engineering, University of Ankara, 06110 Ankara, Turkey \\ IINIZO Food Research, 6718 Ede, the Netherlands
}

\begin{abstract}
The formation of volatile compounds in Turkish Divle Cave cheese produced in 3 different dairy farms was determined during production and ripening, revealing 110 compounds including acids, alcohols, ketones, esters, and terpenes. The presence and concentration of these volatile compounds varied between specific phases of the production and the 120-d ripening process. Smaller differences were also detected between cheeses produced at different farms. Carboxylic acids were established as a major class at the end of ripening. The relative amounts of acids and ketones increased until d 90 of ripening, whereas alcohols increased for the first $30 \mathrm{~d}$ and tailed off during the remaining part of the ripening process. The level of esters increased gradually until the end of ripening. Butanoic, acetic, and valeric acids, 2-butanol, 2-butanone, 2-heptanone, ethyl butanoate, $\alpha$-pinene, and toluene were the most abundant compounds, likely contributing to the characteristic aroma of this traditional cheese.
\end{abstract}

Key words: volatile, ewe cheese, ripening, traditional, Divle

\section{INTRODUCTION}

Fermented milk products typically contain a wide range of flavors that are the result of biochemical conversions of milk components such as lactose, caseins, and milk fat. In cheese, the majority of flavors are derived from proteolytic processes and the subsequent conversion of AA (Visser, 1993). In industrial cheese

\footnotetext{
Received December 28, 2015.

Accepted March 9, 2016.

${ }^{1}$ Corresponding author: budak@ankara.edu.tr or s.budak@cbs. knaw.nl
}

productions, starter cultures are typically added to milk fermentations, greatly accelerating the process of flavor formation, as these bacteria harbor efficient proteolytic systems and AA-converting enzymes, resulting in the formation of a wide range of volatile compounds during production and ripening (Yvon and Rijnen, 2001; Smit et al., 2005).

Raw milk and raw milk cheeses typically also contain lactic acid bacteria and these strains possess AA-converting enzymes with higher or more diverse activities as compared with industrial dairy cultures, resulting in cheeses of more diverse and intense flavor (Centeno et al., 2002; Settanni and Moschetti, 2010). Moreover, other bacterial species, either naturally present in milk or contaminants added in during the handling of the milk, are present in raw milk, and albeit less controlled, play an important role in aroma development by their wide range of enzymes such as proteases and lipases (Chávez et al., 2010).

Divle Cave cheese is a semi-hard cheese made from raw semi-skimmed ewe milk. It is produced in May and June when milk is abundant, in Karaman, a rural region in the middle of Turkey. The ripening takes place in Divle Cave, which is located in the south of this region. The average temperature in the cave is 5 to $10^{\circ} \mathrm{C}$ with a humidity of 85 to $90 \%$. The cheeses are produced without using any starter culture and are ripened for $4 \mathrm{mo}$ in goatskin bags at a depth of approximately $70 \mathrm{~m}$ (Ozturkoglu-Budak et al., 2015). The surface of the goatskin bags changes from green to red during ripening in the cave, and this red color is the distinguishing characteristic of Divle Cave cheese (Figure 1), when compared with other spontaneously mold growing cheeses from Turkey (e.g., Kuflu cheese). Divle Cave cheese has a crumbly texture and a pungent flavor. Moreover, a large variety of aroma compounds occur in this cheese, likely as a consequence of the contribution of the diverse bacterial community present in raw milk (Ozturkoglu-Budak et al., 2015). 


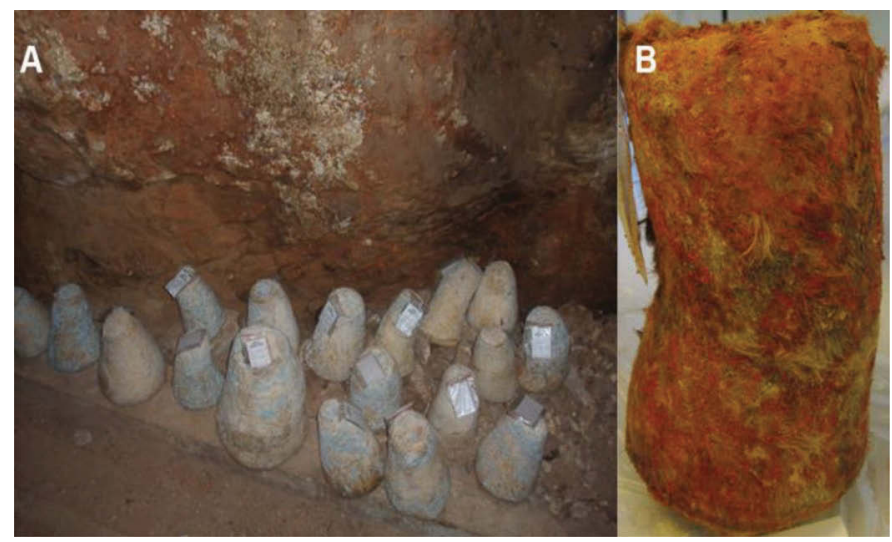

Figure 1. Growth of microorganisms on the surface of goatskin bags during the ripening period of Divle Cave cheese. (A) A view from the cave on d 30 during ripening, (B) appearance of the goatskin bag at the end of the ripening (on d 120). This figure is reprinted by permission of Int. Dairy J. (Ozturkoglu-Budak et al., 2015; doi: 10.1016/j. idairyj.2015.09.011). Color version available online.

So far, studies on the flavor of Divle Cave cheese focused on the products at the end of ripening (Hayaloglu and Karabulut, 2013), but no studies have been published on the development of the volatile profile during production and ripening, which was the aim of this research. This paper presents data that contribute to a better characterization of Divle Cave cheese and these data will help to determine the authenticity of Divle Cave cheese in the future. The obtained data will also be useful for future comparative studies, both on mold-ripened cheeses and on raw ewe milk cheeses, enabling identifications of key flavor compounds that determine the unique taste of each of these cheeses.

\section{MATERIALS AND METHODS}

\section{Cheese Production}

Divle Cave cheeses were produced according to the traditional process and ripened in the Divle Cave (Ozturkoglu-Budak et al., 2015). Standardized semiskimmed raw ewe milk was coagulated with calf rennet at 30 to $32^{\circ} \mathrm{C}$ for $80 \mathrm{~min}$. The coagulum was cut into small sizes, heated to 55 to $60^{\circ} \mathrm{C}$ for 4 to $5 \mathrm{~min}$, and the curd was placed into cotton cloths for whey drainage for 2 to $3 \mathrm{~h}$. To remove the whey, pressure was applied to the cotton bag containing the curd at room temperature for one night. The resulting curd was rinsed with water for $24 \mathrm{~h}$ for complete removal of the whey. Subsequently, cheese blocks were dried by overnight storage at room temperature. The curd was broken into small pieces by hand, dry-salted, and tightly pressed into salted and dried goatskin bags. The goatskin bag was subsequently closed by sewing and pierced with needles to avoid serum loss. At the pre-ripening stage, goatskin bags were kept under cool storage conditions $\left(15-20^{\circ} \mathrm{C}\right)$ until whey drainage stopped, in a process that took 7 to $10 \mathrm{~d}$. Finally, the cheeses were left in Divle Cave for 4 mo for ripening.

\section{Cheese Sampling}

Cheese productions were carried out in 3 different dairy farms (DF1, DF2, and DF3) in the Karaman province of Turkey. Two independent batches were produced by each of the 3 farms with an interval of 15 d. We monitored and controlled all 6 productions and collected samples from each batch at the stages that the raw milk was obtained, and whey and curd were produced, and from cheeses at d 1, 30, 60, 90, and 120 during ripening. Each cheese sample consisted of one goatskin bag of cheese $(3-5 \mathrm{~kg})$. Ten goatskin bags of cheese were prepared per each batch and put in the cave. At each sampling day, duplicate goatskin bags were collected from the cave for analyses. A total of 60 different goatskin bags were analyzed in both batches produced in $3 \mathrm{DF}$. All samples were transported to the laboratory at $4^{\circ} \mathrm{C}$, and divided into different aliquots that were stored at $-20^{\circ} \mathrm{C}$ before analysis. Analyses were performed in triplicate from different parts of cheeses in each goatskin bag. The reported values are the means of the 2 independent batches per DF.

\section{Physicochemical Analyses}

Titratable acidity (as \% of lactic acid) was measured according to AOAC International (1995). The $\mathrm{pH}$ was measured by direct insertion of a $\mathrm{pH}$-meter electrode (MP 225 Mettler Toledo, Columbus, OH) into the slurry sample obtained by maceration of a $10-\mathrm{g}$ sample with $10 \mathrm{~mL}$ of distilled water. Dry matter was analyzed by the oven drying method at $102^{\circ} \mathrm{C}$ (IDF, 1982), whereas salt content was determined by titration with $\mathrm{AgNO}_{3}$ (IDF, 1988). Fat content was measured by the Gerber-Van Gulik method (Ardo and Polychroniadou, 1999), and water-soluble nitrogen (WSN) as well as total nitrogen $(\mathbf{T N})$ were determined by applying the micro-Kjeldahl method on fractions of the cheese prepared as described by IDF (1993). Ripening index (RI) values were calculated according to the ratio of WSN content to total nitrogen content $[\mathrm{RI}=(\mathrm{WSN} / \mathrm{TN})$ $\times 100]$. In the milk, whey and curd samples the $\mathrm{pH}$, titration acidity, DM, and fat content was measured, whereas in the cheese samples these measurements were complemented with WSN and TN measurements. All analyses were performed in triplicate. 


\section{Volatile Compound Analyses}

Volatile compounds were extracted according to the method of (Lee et al., 2003) with minor modifications. Briefly, $5 \mathrm{~g}$ of cheese were positioned in a $20-\mathrm{mL}$ vial, followed by the addition of $5 \mathrm{~mL}$ of $\mathrm{NaCl}(10 \%$, wt/vol) and $10 \mu \mathrm{L}$ of Internal Standard (2 methyl-3 heptanone and 2-methylpentanoic acid). The vial was placed in a magnetic stirrer at $60^{\circ} \mathrm{C}$ for $30 \mathrm{~min}$ for equilibrium of volatile compounds in the headspace. Extraction of volatile compounds was carried out by injecting $75 \mu \mathrm{m}$ of carboxen/polydimethylsiloxane solid-phase microextraction (SPME) fiber (Supelco, Bellefonte, PA) into the vial and exposure of the fiber to the headspace for $30 \mathrm{~min}$ at $60^{\circ} \mathrm{C}$. During extraction, the sample was stirred continuously with a magnetic stir bar. The volatile compounds were desorbed by direct insertion of the fiber into the injection port of the GC, which was operated in splitless mode at $250^{\circ} \mathrm{C}$ for 3 min.

Volatile compound analyses were performed by employing the SPME-GC-MS method. Headspace volatile compounds were analyzed using an Agilent 7890 GC system (Agilent Technologies, Santa Clara, CA) coupled to a mass spectrometer (Agilent 5975C VL MSD with Triple-Axis detector). The GC was equipped with a DB-Wax column $(30 \mathrm{~m}, 0.25 \mathrm{~mm}$ i.d., and $0.25 \mu \mathrm{m}$ film thickness) and a split/splitless injector. Helium was used as carrier gas at a flow rate of $1 \mathrm{~mL} / \mathrm{min}$. The initial temperature program employed was isothermal at $40^{\circ} \mathrm{C}$ for $10 \mathrm{~min}$, followed by elevation of the temperature to $110^{\circ} \mathrm{C}$ at a rate of $5^{\circ} \mathrm{C} / \mathrm{min}$ and $240^{\circ} \mathrm{C}$ at a rate of $10^{\circ} \mathrm{C} / \mathrm{min}$ with a final extension of $5 \mathrm{~min}$ at $250^{\circ} \mathrm{C}$. Mass spectra were recovered in the electron impact mode at an ionization voltage of $70 \mathrm{eV}$, and data were collected at a rate of 3.2 scans/s over a range of $\mathrm{m} / \mathrm{z} 35$ to 500 . Data were analyzed under the same conditions to calculate retention indices for the volatile compounds. Identification of volatile compounds was achieved by comparison to n-alkanes (C4-C20) standards (Sigma-Aldrich, St. Louis, MO) and by comparison of their mass spectra with those in the libraries of Wiley, National Institute of Standards and Technology (NIST), and Flavor (Agilent MSD Chemstation, Santa Clara, CA). The concentration of each compound was calculated by the ratio of the peak area of the internal standard and the unknown compound. Samples were analyzed in triplicate.

\section{Statistical Analyses}

The significance of the differences observed in the physicochemical analyses and volatile profiles during production and ripening were assessed by using the ANOVA procedure of the SPSS Statistics software ver- sion 22.0 (IBM Corp., Armonk, NY). One-way ANOVA, followed by a Duncan's multiple comparison test, was used for statistical analysis to determine if there was a significant difference $(P<0.05)$ between treatments. Principal component analysis was performed using a covariance matrix and varimax rotation between production and ripening stages. The concentration of volatile compounds were used as variables.

\section{RESULTS AND DISCUSSION}

\section{Physicochemical Parameters}

The temporal development of acidity, pH, DM, and fat during production, as well as salt and protein content during ripening, are given in Tables 1 and 2, respectively. During cheese production (from raw milk to the first day of ripening) the $\mathrm{pH}$ decreases dramatically, similar to what is typically observed for industrial cheeses, and which is likely caused by available lactic acid bacteria (Ozturkoglu-Budak et al., 2015) converting lactose to lactic acid. Afterward, other organisms become more dominant and concomitantly the $\mathrm{pH}$ increases throughout the ripening. Specific yeast and fungi could be responsible for this $\mathrm{pH}$ increase, because these organisms can metabolize the lactate produced by lactic acid bacteria to $\mathrm{CO}_{2}$ and $\mathrm{H}_{2} \mathrm{O}$ (Schlesser et al., 1992). Moreover, deamination of AA in the later stages of ripening (Schlesser et al., 1992), formation of ammonia and other proteolysis products with amphoteric characteristic, as well as the fragmentation of fatty acids into methyl ketones (McSweeney, 2004), could contribute to the elevation of $\mathrm{pH}$ observed. Not surprisingly, a low $\mathrm{pH}$ typically co-occurred with a high level of acidity, and vice versa.

Fat, salt, and DM content showed a slight increase during ripening. It is considered that the increase observed in salt and fat content in early days of ripening results from relative DM increase caused by evaporation. A further increase occurred after d 90 of ripening, which has been reported to depend on removal of fragmented products formed as a result of proteolytic and lipolytic enzyme activities, associated with the microbial community present in cheese samples (Hayaloglu et al., 2007a). A decrease in TN content was observed in the early stages of ripening, whereas an increase was seen after $\mathrm{d} 60$ until the end of the ripening period. Changes in DM content could affect the nitrogen content. Water-soluble nitrogen rates of cheese samples appeared to increase during the ripening period. It has previously been established that heat treatment applied to milk and salt content can affect the WSN content (Guinee, 2004). Moreover, it was reported that lactic acid bacteria can perform proteolysis even after the ripening 
Table 1. Gross composition of raw milk, whey, and curd during the production of Divle Cave cheese (mean $\pm \mathrm{SD} ; \mathrm{n}=3)$

\begin{tabular}{|c|c|c|c|c|}
\hline \multirow[b]{2}{*}{ Item } & \multirow[b]{2}{*}{ Dairy farm (DF) } & \multicolumn{3}{|c|}{ Production of cheese } \\
\hline & & Raw milk & Whey & Curd \\
\hline \multirow[t]{3}{*}{$\overline{\mathrm{pH}}$} & DF1 & $6.75 \pm 0.00^{\mathrm{C}, \mathrm{a}}$ & $6.64 \pm 0.01^{\mathrm{B}, \mathrm{c}}$ & $4.89 \pm 0.07^{\mathrm{A}, \mathrm{a}}$ \\
\hline & $\mathrm{DF} 2$ & $6.75 \pm 0.01^{\mathrm{C}, \mathrm{a}}$ & $6.61 \pm 0.01^{\mathrm{B}, \mathrm{b}}$ & $4.97 \pm 0.012^{\mathrm{A}, \mathrm{a}}$ \\
\hline & DF3 & $6.74 \pm 0.01^{\mathrm{C}, \mathrm{a}}$ & $6.55 \pm 0.02^{\mathrm{B}, \mathrm{a}}$ & $5.06 \pm 0.017^{\mathrm{A}, \mathrm{b}}$ \\
\hline \multirow[t]{3}{*}{ Acidity $\left({ }^{\circ} \mathrm{SH}^{1}\right)$} & DF 1 & $12.45 \pm 0.02^{\mathrm{B}, \mathrm{b}}$ & $6.89 \pm 0.18^{\mathrm{A}, \mathrm{b}}$ & $66.65 \pm 0.27^{\mathrm{C}, \mathrm{c}}$ \\
\hline & $\mathrm{DF} 2$ & $12.87 \pm 0.04^{\mathrm{B}, \mathrm{c}}$ & $6.14 \pm 0.09^{\mathrm{A}, \mathrm{a}}$ & $62.8 \pm 0.86^{\mathrm{C}, \mathrm{b}}$ \\
\hline & DF3 & $11.75 \pm 0.04^{\mathrm{B}, \mathrm{a}}$ & $6.2 \pm 0.12^{\mathrm{A}, \mathrm{a}}$ & $59.45 \pm 1.07^{\mathrm{C}, \mathrm{a}}$ \\
\hline \multirow[t]{3}{*}{$\mathrm{DM}(\% \mathrm{wt} / \mathrm{wt})$} & DF1 & $19.17 \pm 0.07^{\mathrm{B}, \mathrm{b}}$ & $8.49 \pm 0.06^{\mathrm{A}, \mathrm{a}}$ & $34.18 \pm 0.48^{\mathrm{C}, \mathrm{ab}}$ \\
\hline & $\mathrm{DF} 2$ & $19.52 \pm 0.10^{\mathrm{B}, \mathrm{c}}$ & $8.78 \pm 0.17^{\mathrm{A}, \mathrm{b}}$ & $32.97 \pm 0.64^{\mathrm{C}, \mathrm{a}}$ \\
\hline & DF3 & $18.96 \pm 0.09^{\mathrm{B}, \mathrm{a}}$ & $8.22 \pm 0.09^{\mathrm{A}, \mathrm{a}}$ & $35.80 \pm 0.85^{\mathrm{C}, \mathrm{b}}$ \\
\hline \multirow[t]{3}{*}{ Fat (\% wt/wt) } & DF 1 & $4.68 \pm 0.02^{\mathrm{B}, \mathrm{b}}$ & $1.20 \pm 0.07^{\mathrm{A}, \mathrm{a}}$ & $9.38 \pm 0.02^{\mathrm{C}, \mathrm{b}}$ \\
\hline & $\mathrm{DF} 2$ & $4.60 \pm 0.08^{\mathrm{B}, \mathrm{ab}}$ & $1.35 \pm 0.07^{\mathrm{A}, \mathrm{ab}}$ & $9.00 \pm 0.08^{\mathrm{C}, \mathrm{a}}$ \\
\hline & DF3 & $4.47 \pm 0.06^{\mathrm{B}, \mathrm{a}}$ & $1.45 \pm 0.08^{\mathrm{A}, \mathrm{b}}$ & $8.85 \pm 0.08^{\mathrm{C}, \mathrm{a}}$ \\
\hline
\end{tabular}

period is over (e.g., during storage), thereby affecting the nitrogen content (Carbonell et al., 2002). Taken together, despite the fact that Divle Cave cheese has a distinctly different taste as compared with industrially produced hard cheeses, the temporal development of the basic process parameters is comparable.

Table 2. Gross composition of Divle Cave cheese during ripening (mean $\pm \mathrm{SD} ; \mathrm{n}=3$ )

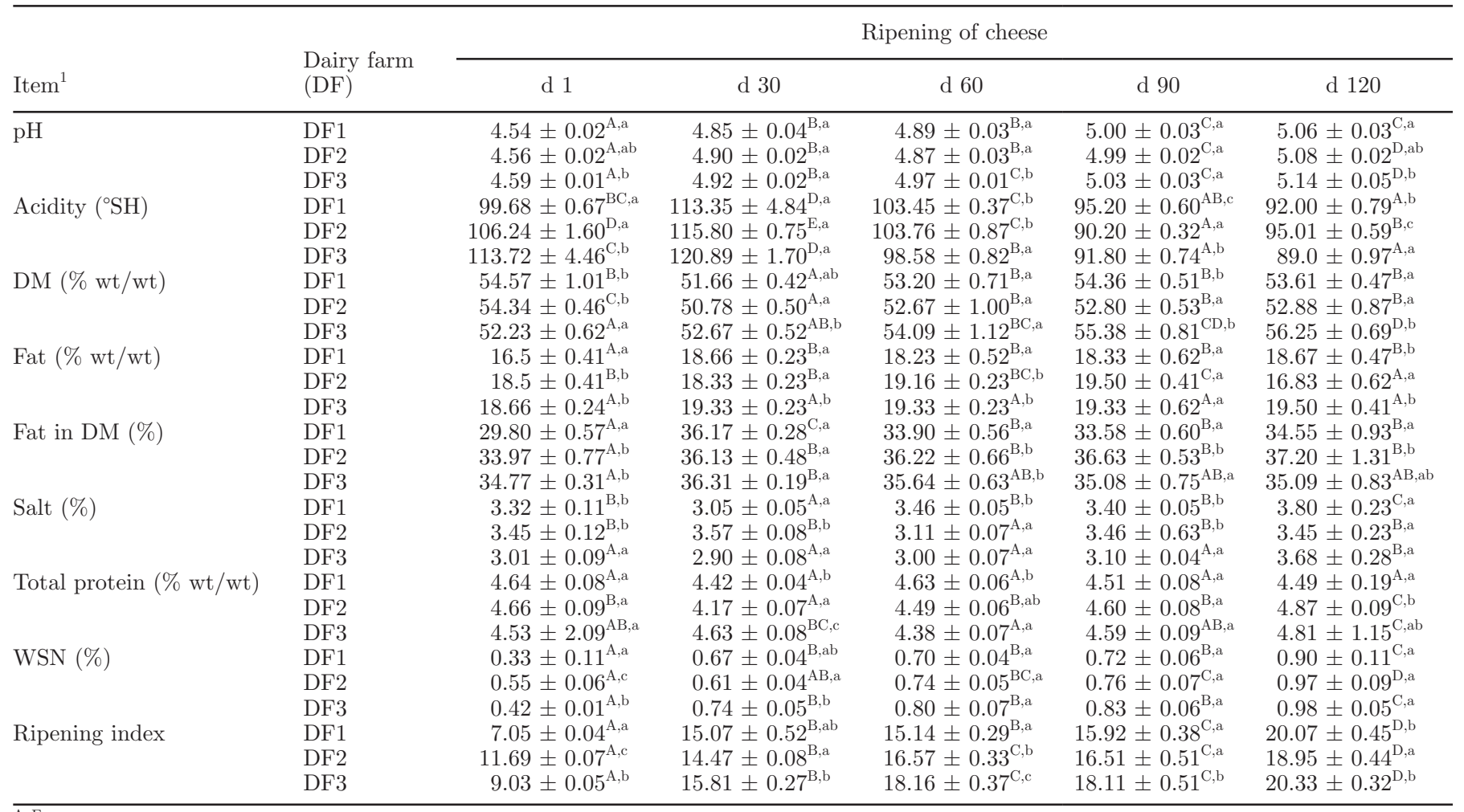

\footnotetext{
${ }^{\mathrm{A}-\mathrm{E}}$ Means within a row with different uppercase letters show significant differences between ripening times, $P<0.05$.

${ }^{\mathrm{a}-\mathrm{c}}$ Means within a column with different lowercase letters show significant differences between dairy farms, $P<0.05$.

${ }^{1}{ }^{\circ} \mathrm{SH}=$ degrees Soxhlet-Henkel; WSN = water-soluble nitrogen. Ripening index is the progress of the maturation process during the ripening stages.
} 


\section{Volatile Compound Profiles}

We detected a total of 110 volatile compounds derived from Divle Cave cheese during production and ripening by SPME-GC-MS (Supplemental Table S1; http://dx.doi.org/10.3168/jds.2015-10828). These volatiles encompass 13 acids, 18 alcohols, 12 ketones, 15 esters, 12 terpenes, 7 aldehydes, 18 hydrocarbons, and 15 miscellaneous compounds.

Figure 2 shows the variation of the volatile compounds per chemical group isolated from Divle Cave cheese produced in the $3 \mathrm{DF}$. The chemical group encompassing the carboxylic acids displayed an increase until d 90 of ripening in all DF. Moreover, carboxylic acids appeared the most abundant group of volatiles in the cheese at the end of ripening. The level of alcohols tended to increase in the initial stages of ripening ( $\mathrm{d} 30$ in DF1 and d 60 in DF2 and 3), followed by decreasing levels in the final stages of ripening. Ketones gradually increased during $90 \mathrm{~d}$, and slightly decreased in the last 30 of ripening. Esters increased gradually until d 90 of ripening, a process that continued in the last $30 \mathrm{~d}$ in DF1 and DF3. The level of hydrocarbons and miscellaneous compounds was highly variable during ripening and at the different farms but tended to increase at the end of ripening. Aldehydes also showed an increasing abundance during ripening. Terpenes were found in higher amounts in raw milk and curd, whereas their levels decreased on d 1 , followed by increasing levels after that time, until the end of ripening. Notably, in the raw milk used at the $3 \mathrm{DF}$ distinct differences were observed for the abundance of chemical groups such as acids and alcohols. However, these differences were virtually abolished at the curd stage and beyond, suggesting that variations in the final fermentation product are relatively minor, indicating the robustness of this wild fermentation process.

\section{Carboxylic Acids}

In Divle Cave cheese, lipolysis is thought to be the main pathway for the formation of carboxylic acids, followed by lactose metabolism. Carboxylic acids are not only aroma components as such, but can also serve as precursors for the formation of methyl ketones, alcohols, lactones, aldehydes, and esters (Collins et al., 2003). Due to their low detection thresholds $(<5 \mathrm{mg} /$ $\mathrm{kg})$, short-chain (C4-C8) and medium-chain (C10-C14) carboxylic acids are thought to contribute significantly to the aroma profile of cheeses (Tavaria et al., 2004).

The temporal flavor profiles in the Divle Cave cheese revealed 13 carboxylic acids with comparable total volatile headspace percentages of $30.79,32.97$, and $25.30 \%$ at the end of ripening in the $3 \mathrm{DF}$ (Supplemental Table
S1; http://dx.doi.org/10.3168/jds.2015-10828). Similar carboxylic acid levels were previously reported in sheep cheeses. Bergamini et al. (2010) identified 11 acids in Argentinean sheep cheeses, Hayaloglu et al. (2008) identified 11 acids in Kuflu cheese, and Delgado et al. (2010) determined 13 acids in Torta Del Casar cheese made from raw ewe milk. Fifty to sixty percent of acids, especially short-chain fatty acids, were found in Spanish sheep cheeses (Barron et al., 2005). We observed significant differences $(P<0.05)$ in total amount of carboxylic acids both throughout the ripening period in the same production as well as among different productions in different dairy farms. For specific lowly abundant carboxylic acids, different absence/presence profiles were observed in different DF; however, the highly abundant carboxylic acids were always found in all $3 \mathrm{DF}$, suggesting that the production site only generates minor differences in flavor, which is likely to be largely overruled by the much longer ripening process in Divle Cave.

Among linear-chain fatty acids, that are formed by the hydrolysis of triglycerides, short-chain fatty acids were found to be predominant components of aroma as in raw ewe milk cheese such as Torta del Casar (Delgado et al., 2010) and mold-ripened cheese such as Blue cheese (Rothe et al., 1994). To this end, butanoic (butyric) and pentanoic (valeric) acid were detected at high levels at the end of ripening of cheeses in all $3 \mathrm{DF}$. These components have been established to be present at high levels in industrial cheeses as well (Yvon and Rijnen, 2001), and butanoic acid is perceived as a rancid cheese-like smell (Sablé and Cottenceau, 1999). The other linear-chain acids identified in the headspace of Divle Cave cheese were hexanoic, octanoic, and decanoic acids. Especially hexanoic acid was detected at high levels in Divle Cave cheese produced at all dairy farms. Hexanoic acid has been reported to make a significant contribution to the aroma of sheep cheeses, such as Torta del Casar cheese (Delgado et al., 2010), traditional Greek Xinotyri type cheese (Bontinis et al., 2012), and Teleme cheese (Massouras et al., 2006).

Acetic acid was the second highest abundant and frequently detected acid during the ripening. Acetic acid results from the activity of lactic acid bacteria, and it is perceived as a pungent aroma that gives the typical aroma to brine-cured cheese types such as Feta and Domiati (Hayaloglu and Karabulut, 2013). In our study, the increase in acetic acid content, which continued until d 90 of ripening, turned into a decrease at d 120. This result was associated with mold content, which increased toward the end of ripening and lactic acid bacteria content, which decreased in the last $30 \mathrm{~d}$ (Ozturkoglu-Budak et al., 2015). 
A

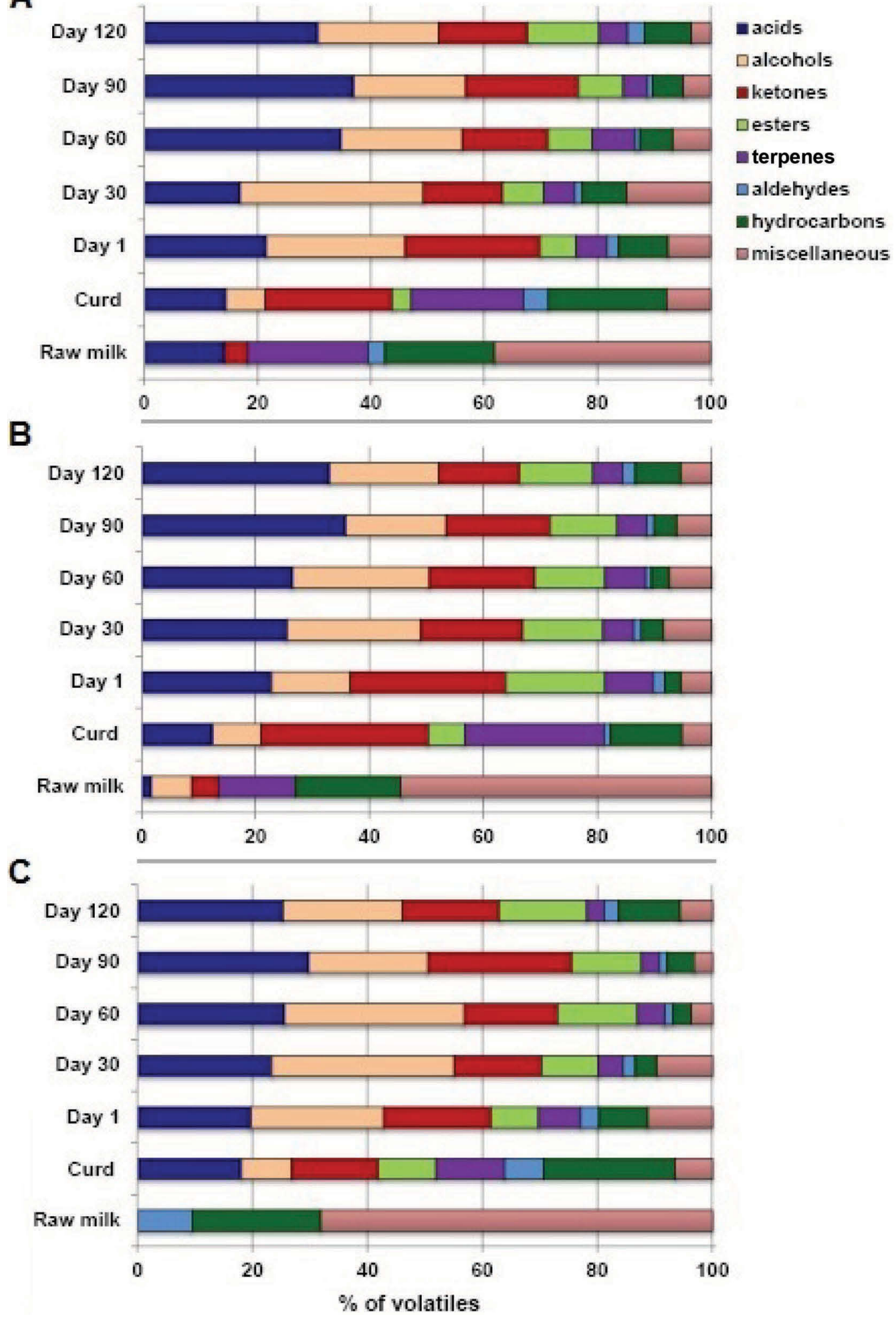

Figure 2. Variation of the main chemical groups of volatile compounds isolated from Divle Cave cheese during production and ripening. A, $\mathrm{B}$, and $\mathrm{C}$ represent the cheeses produced in dairy farm (DF) 1, DF2, and DF3, respectively. Color version available online. 
Branched-chain fatty acids have been reported to have a characteristic effect on flavors of sheep and goat cheeses (Curioni and Bosset, 2002). In our study, it was established that 3-methyl butanoic acid (isovaleric acid) was the most abundant branched-chain fatty acid in Divle Cave cheese samples and showed a continuous increase until the end of ripening. This acid is reported to give rancid, cheese-like, and sweet flavoring to sheep cheeses (Yvon and Rijnen, 2001). The high amount of acids synthesized from AA may be associated with severe proteolysis in Divle Cave cheese due to enzymes derived from the raw milk (Carbonell et al., 2002). It was reported previously that 3-methyl butanoic acid was the most perceived acid in terms of olfactometry in a semi-hard Spanish goat cheese (Delgado et al., 2011).

\section{Alcohols}

Alcohols have been reported at high concentrations in Blue cheeses and some surface-ripened cheeses such as Camembert, Brie, and Gorgonzola. It has also been established that particularly enzymes secreted by Penicillium roqueforti and Penicillium camemberti play an active role in the formation of alcohols (Molimard and Spinnler, 1996). Moreover, alcohols were reported as the main volatile component in some hard and long ripened cheeses such as Cheddar, Kaşar, and Tulum (Curioni and Bosset, 2002) and in raw ewe milk cheeses (Bintsis and Robinson, 2004; Fernández-Garcia et al., 2004). In addition, ethanol was quantitatively determined as the main alcohol in some of these cheeses (Bontinis et al., 2012).

We detected 14 to 18 different alcohols, depending on the DF (Supplemental Table S1; http://dx.doi. org/10.3168/jds.2015-10828), and included primary, secondary, branched-chain, unsaturated, and aromatic alcohols. These findings are in agreement with the results of Wolf et al. (2010) and Bergamini et al. (2010) who found 15 and 14 alcohols in Reggianito and Argentinean sheep cheeses, respectively. Hayaloglu et al. (2008) found 32 alcohols among the main volatile group in Kuflu cheese varying between 189.89 to 270.75 peak area/105 of total alcohols. Similarly, Pappa et al. (2013) reported an increase in alcohols levels during the ripening and found high amounts of alcohols at the end product of Teleme cheese. Significant $(P<0.05)$ variations were observed in total amount of alcohols both throughout the ripening period in the same production and among different productions in different dairy farms.

The use of raw milk is likely to be the reason of relatively high alcohol concentrations in Divle Cave cheese. Particularly, high ethanol concentration detected at the stages of curd, and d 1 and 30 of ripening could originate from the lactic acid bacteria, enterococci, and yeast in the microbial populations coming from raw milk and the cheese processing environment (Bontinis et al., 2012). 2-Butanol, ethyl alcohol, and 1-pentanol were the most abundant alcohols during the production and ripening periods (Supplemental Table S1; http://dx.doi.org/10.3168/jds.2015-10828). Secondary alcohols such as 2-butanol, 2-heptanol, 2-octanol, and 2-pentanol were found at the highest concentration among all alcohols at the end of ripening. 2-butanol was the most abundant, followed by 2-pentanol, 2-heptanol, 2-octanol, and 1-heptanol. Interestingly, 2-butanol also is the most abundant alcohol in Spanish Manchego cheese (Gómez-Ruiz et al., 2002). It is a secondary alcohol typically formed from diacetyl (2,3-butanedione) especially in raw milk cheeses. Diacetyl is degraded to acetoin by the bacterial enzymes coming from raw milk, after which it is reduced to 2,3-butandiol, subsequently to 2-butanone, and finally to 2-butanol (Bontinis et al., 2012). Notably, 2-pentanol has a low detection threshold and is reported to play an important role in cheese aroma (Carbonell et al., 2002). 2-Heptanol was identified as a key odorant of Gorgonzola and Grana Padano cheeses (Curioni and Bosset, 2002; Poveda and Cabezas, 2006). An increase was detected in the relative amounts of some alcohols such as ethanol, 1-pentanol, 2-butanol, and 2,3-butanediol, until d 30 of ripening, whereas the levels tended to decrease from that point in the ripening process onward.

\section{Ketones}

Methyl ketones are formed by the enzymatic activities of molds and fungi (Molimard and Spinnler, 1996) and have typical odors detectable at a low perception threshold. For this reason these compounds are important in the aroma of Camembert, raw ewe milk cheese (Di Cagno et al., 2003), and Blue cheeses (Hayaloglu et al., 2007b).

In total, we detected 12 ketones during the production and ripening of Divle Cave cheese and the majority of them belong to methyl ketones (Supplemental Table S1; http://dx.doi.org/10.3168/jds.2015-10828). Similar results were obtained in Reggianito cheese made from ewe milk (Wolf et al., 2010) and in Kuflu cheese (Hayaloglu et al., 2008). Twenty ketones were determined in Kuflu cheese varying between 163.50 to 285.89 peak area/105 of total ketones (Hayaloglu et al., 2008). We observed significant $(P<0.05)$ differences in total amount of ketones both throughout the ripening period in the same production and among different productions in different dairy farms. 
Diacetyl (2-3-butanedione) was determined as an odor contributor compound in Cheddar, Camembert, and Emmental cheeses (Yvon and Rijnen, 2001) and was also readily detected here, in a decreasing trend. Moreover, the typical ewe milk methyl ketones 2-butanone, 2-pentanone, and 2-heptanone (Gómez-Ruiz et al., 2002; Barron et al., 2007) were the most abundant ketones in all dairy farms during ripening. They were detected at a low level in milk and curd, but greatly increased after pre-ripening (on d 1) in all productions, and continued to increase until d 90 of ripening, and tended to decrease at the end of ripening. The reason of increase observed in the concentration of methyl ketones until d 90 of ripening could be due to the catabolism of free fatty acids, derived from the lipolysis, to methyl ketones by microorganisms (Bontinis et al., 2012), whereas the declines observed at the end of ripening can be explained by the enzymatic reduction of ketones to secondary alcohols depending on their intermediate compounds (Curioni and Bosset, 2002). 2-Butanone and 2-heptanone have specific odors classified as herbaceous and butter scotch, respectively (Delgado et al., 2011) and have been described as primary ketones in some raw ewe milk cheeses such as La Serena (Carbonell et al., 2002), Zamarano (Fernández-García et al., 2004), Torta del Casar (Delgado et al., 2010). 2-Butanone was determined as principal ketone in Xinotyri (Bontinis et al., 2012) and Teleme (Massouras et al., 2006) cheeses. Furthermore, 2-heptanone is an important component of Emmental and Gorgonzola cheeses (Curioni and Bosset, 2002). 2-Nonanone and 2-octanone were also reported to have typical odors and have low perception threshold in dairy products (Hayaloglu et al., 2007a).

Acetoin (3-hydroxy 2-butanone) is another ketone following a decreasing trend. The reduction in the acetoin amount could be thought of as a result of the decrease in diacetyl because it is synthesized by the reaction of diacetyl with the enzymes from bacteria present in raw milk, or it may be produced from lactose, citrate, or pyruvate by lactic acid bacteria (Di Cagno et al., 2003). For that reason, the reduction in the amount of diacetyl or lactic acid bacteria content causes a reduction in acetoin.

\section{Esters}

Esters are formed by the esterification of short-chain free fatty acids with alcohols (Delgado et al., 2010). Esters have a floral and fruity aroma and contribute to the reduction of the sharpness of fatty acids and bitterness of amines (Gallois and Langlois, 1990; Bontinis et al., 2012). Esters are highly effective in cheese aroma because of their low perception threshold values (Molimard and Spinnler, 1996).
We detected 15 esters that were not found in all dairy farms, pinpointing that subtle differences in taste observed for cheeses derived from different DF might be caused by the variations in ester-type components. Nevertheless, ethyl esters were the most abundant esters detected in the headspace of Divle Cave cheese. Ethyl butanoate, ethyl hexanoate, butyl acetate, and isopenthyl formate were detected frequently and abundantly. The increased detection of ethyl butanoate may be related to the decrease of butanoic acid at the end of the ripening. We observed an increase $(P<0.05)$ in ethyl acetate and ethyl octanoate in the first stage of ripening, which could be related to the increase in yeast and mold count and the decrease could be due to the alcohols that concomitantly decreased at the end of ripening. The increase in the concentration of ethyl hexanoate and ethyl butanoate during ripening were also observed in other ewe cheeses (Carbonell et al., 2002; Barron et al., 2007). Similarly, ethyl acetate and ethyl hexanoate were detected in many traditional cheeses such as Cheddar, Emmental, Gorgonzola, Grana Padano, Pecorino, and Ragusano (Curioni and Bosset, 2002). Moreover, other ethyl esters we identified, (e.g., ethyl butyrate and phenethyl acetate) were previously noticed to contribute to the odor of Cheddar and Camembert cheese, respectively (Yvon and Rijnen, 2001).

\section{Terpenes}

Terpenes are compounds related to animal feed or pasture, green fodder, and meadow (Munoz et al., 2003; Revello Chion et al., 2010). Hence, it is thought that the abundance of terpenes in Divle Cave cheese results from the natural feed of the animals in the Divle district. This is corroborated by our data that show that the ripening process did not affect the terpene concentrations. Many researchers reported that the importance of terpenes in formation of cheese aroma is not certain but these components are frequently identified in cheeses produced from goat and sheep milks (Delgado et al., 2010; Bontinis et al., 2012).

$\alpha$-Pinene is the primary terpene detected at highest concentration at all stages of production and ripening. Other terpenes detected at high concentrations were pcymene, $\beta$-pinene, and $\alpha$-copaene. Generally, terpenes were identified starting from raw milk such as $\alpha$-pinene, camphene, o-cymene, and D-limonene. The highest amounts were detected in curd but the concentrations decreased during ripening, except $\alpha$-pinene in which the concentration increased during ripening.

The level of terpenes fluctuated with a decrease on $\mathrm{d}$ 1 followed by elevated levels until the end of ripening. Terpenes are lipophilic volatile compounds (Borge et 
al., 2016) and derive from milk fat (Viallon et al., 2000) of which the concentration also increases as a result of water loss during ripening. Several other studies showed that terpenes may also be formed by microorganisms such as yeasts and especially Kluyveromyces lactis (Martin et al., 2001) and fungal cultures (Agrawal and Joseph, 2000) in the milk and milk products and they might be changed as a result of microbial activity. Hence, growth of diverse bacteria, yeast, and filamentous fungi in Divle Cave cheese (Ozturkoglu-Budak et al., 2015) might cause the variation in terpene amounts. Similar variations in terpene profile were also reported in milk and milk products (Poulopoulou et al., 2012).

\section{Aldehydes}

Aldehydes have low perception thresholds and are characterized by herbaceous and green-grass-like aroma (Molimard and Spinnler, 1996; Curioni and Bosset, 2002). Seven aldehyde-containing compounds including lactones, sulfurs, phenols, and amines were identified in the volatile fraction of Divle Cave cheese (Supplemental Table S1; http://dx.doi.org/10.3168/jds.2015-10828). Hexanal, 3-methyl-butanal, and benzaldehyde were identified as the major compounds among the all aldehydes. 3-Methyl-butanal has already been established to contribute to Cheddar, Camembert, and Emmental cheese flavor (Yvon and Rijnen, 2001). Hence, our data suggest this is also the case for Divle Cave cheese.

Pentanal, n-octanal, nonanal, and heptanal were irregularly detected during specific stages of production and ripening. The concentrations of aldehydes usually fluctuated during consecutive stages. These fluctuations in their amounts could be originated from their transition properties, conversion into alcohols, and oxidization to their corresponding acids (Molimard and Spinnler, 1996; Munoz et al., 2003).

\section{Hydrocarbons}

Despite the frequent detection of hydrocarbons in cheeses (Delgado et al., 2010, 2011; Bontinis et al., 2012), they do not contribute to cheese aroma for their low detection amounts and high perception threshold. We identified 18 hydrocarbon compounds in the volatile fraction of Divle Cave cheese (Supplemental Table S1; http://dx.doi.org/10.3168/jds.2015-10828). The determined amounts were generally low and fluctuated during production and ripening. Toluene, styrene, and 1,2-dichloro benzene were the most frequently detected hydrocarbons at all stages. Taken together, it appears that hydrocarbons do not play an important role in the flavor profile of DC cheese.

\section{Miscellaneous}

We identified 15 miscellaneous compounds including lactones, sulfurs, phenols, and amines in the volatile fraction of Divle Cave cheese (Supplemental Table S1; http://dx.doi.org/10.3168/jds.2015-10828). Diethyl ether, p-cresol, and m-cresol were frequently detected at high concentrations. Phenolic compounds such as $\mathrm{p}$-cresol and $\mathrm{m}$-cresol were detected starting from curd and in an increasing concentration. p-Cresol (4-methylphenol) is formed by the destruction of tyrosine (Molimard and Spinnler, 1996). Dimethyl disulfide was identified as the only sulfur compound. This compound was reported to contribute particularly to the aroma of mold-ripened cheeses (Bontinis et al., 2012). It originates from the degradation of methionine or methionine-containing peptides during ripening. Perception threshold value for sulfur compounds are usually very low (ppb) and are typically perceived as ripened cheese, garlic, moldy cheese, broccoli, or cooked cabbage $(\mathrm{Cu}-$ rioni and Bosset, 2002; Bontinis et al., 2012). It has been reported that the volatile sulfur compounds contribute to the aroma of many cheese types (McSweeney and Sousa, 2000). Microorganisms such as Penicillium camemberti, Geotrichum candidum, and Brevibacterium linens contribute to the formation of sulfur components because of their ability to form methanethiol (Engels et al., 1997) and detected particularly in surface- and mold-ripened cheeses (Molimard and Spinnler, 1996; McSweeney and Sousa, 2000).

\section{Effect of Production/Ripening Stages and Different Dairy Farms on Cheese Volatile Profile}

We performed principal component analyses (PCA) using the total concentrations of main volatile groups (acids, alcohols, ketones, esters, terpenes, aldehydes, hydrocarbons, and miscellaneous) as variables to identify how the volatile profiles discriminated among the cheeses produced in each dairy farm (DF1, DF2, DF3) and during the production and ripening stages. Table 3 shows the most important loadings and the percentage accounted by the 2 first principal components (PC1, PC2). A scores plot obtained from PCA of raw milk, curd, and 1-, 30-, 60-, 90-, and 120-d-old cheese samples defined by the 2 first principal components (PC1 and PC2) in 3 different dairy farms is shown in Figure 3.

According to the data analysis, PC1 explained $41.69 \%$ of the total variability and was mainly defined by total volatile acids, alcohols, ketones, esters, terpenes, and various miscellaneous compounds. All these compounds were positioned in close proximity and positively correlated with each other. The PC2 explained $23.10 \%$ of 


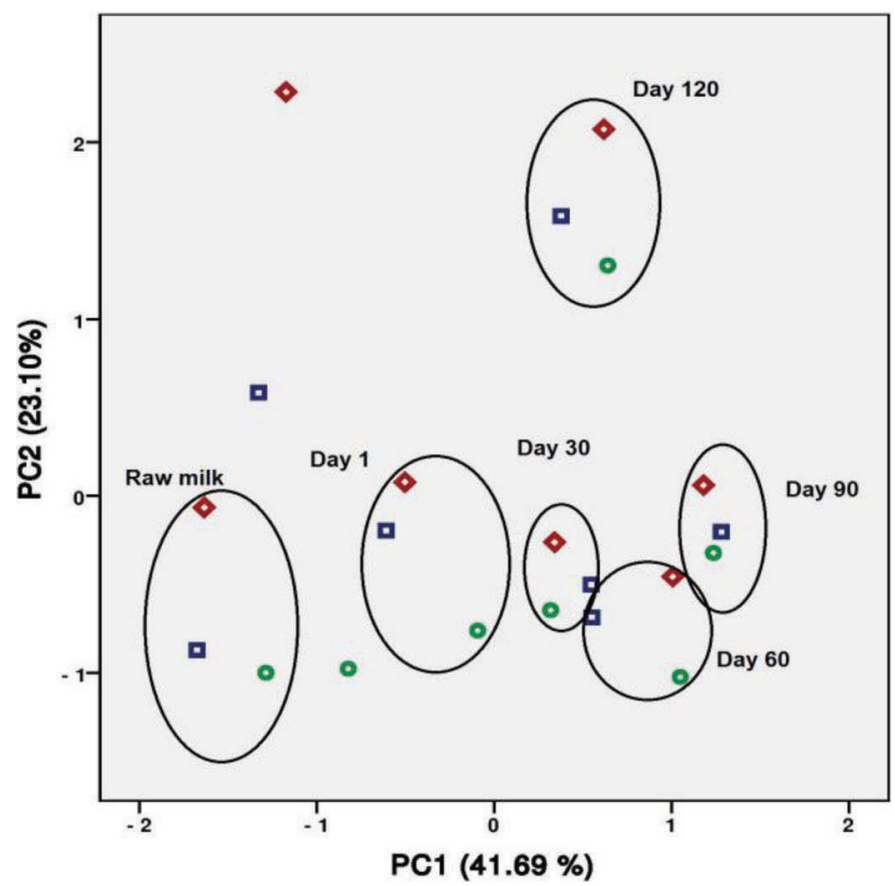

Figure 3. Score plot obtained by principal component (PC) analysis of the individuals in the plane defined by the 2 first PC (PC\#1 and PC\#2) on dairy farm (DF) $1(\square)$, (b) DF2 (○), and (c) DF3 $(\diamond)$. Color version available online.

the total variability and was defined by total aldehydes and hydrocarbons. The PC1 could be considered as representative of the ripening time, because all production stages (raw milk, curd) and d 1 during ripening were clustered on the negative side of PC1, and all cheese samples taken on d 30,60, 90, and 120 were located on the positive side of PC1. Production stages and cheeses at $\mathrm{d} 1$ are located in the negative area of both $\mathrm{PC} 1$ and $\mathrm{PC} 2$. Cheeses at $\mathrm{d} 30$ are near the axis origin. Cheeses with 60 and $90 \mathrm{~d}$ were located following the cheeses of $\mathrm{d}$ 30. The PC2 could explain differences between

Table 3. Principal component analysis: loadings of the total volatile compounds for the first 2 principal components ${ }^{T}$

\begin{tabular}{lcrr}
\hline & \multicolumn{3}{c}{ Component } \\
\cline { 2 - 4 } Item & 1 & \multicolumn{1}{c}{2} & \multicolumn{1}{c}{3} \\
\hline Total acids & 0.844 & 0.238 & 0.186 \\
Total alcohols & 0.933 & 0.044 & -0.122 \\
Total ketones & 0.909 & 0.044 & 0.165 \\
Total esters & 0.877 & 0.283 & 0.051 \\
Total terpenes & 0.285 & -0.039 & 0.843 \\
Total aldehydes & 0.210 & 0.931 & 0.072 \\
Total hydrocarbons & 0.135 & 0.872 & 0.144 \\
Total miscellaneous & 0.124 & -0.280 & -0.793 \\
\hline
\end{tabular}

${ }^{1}$ Extraction method $=$ principal component analysis. Rotation method $=$ Varimax with Kaiser normalization; rotation converged in 5 iterations. cheeses at d 120 and the cheeses obtained in the former periods of ripening $(30,60$, and $90 \mathrm{~d}$ ) because $120-\mathrm{d}$-old ripened cheeses were in the upper part of the plane and the former ones were in the low part of the plane, indicating that long-term ripening (over $90 \mathrm{~d}$ ) leads to a significantly different cheese. This indicates that the volatile profile of Divle Cave cheeses were similar at the beginning of ripening but different aromatic profiles were formed at the end of ripening in each DF. It also showed cheeses had higher contents of aldehydes and hydrocarbons at $\mathrm{d} 120$. Although the milk from the 3 DF cluster in our PCA analysis, the curds from the DF appear substantially different, whereas at the end of the ripening the cheeses from the all DF are highly similar. This result demonstrates that cheese production is an artisanal and variable process, but these differences are eliminated during the long ripening period in which all cheeses are placed in the same cave.

\section{CONCLUSIONS}

The study presented here established for the first time the composition of 110 volatiles of Divle Cave cheese during production and ripening, and identified the indigenous and characteristic volatile components. Carboxylic acids resulting from lipolysis of triglycerides, mainly butanoic and pentanoic acids, were found to be most abundant. Alcohols, ketones, and esters were determined as the other major volatile groups, likely caused by the high count of yeast and mold in Divle cheese. Short-chain fatty acids, secondary alcohols, methyl ketones, and ethyl esters were detected both frequently and at high concentration at different stages of the ripening process. Different terpene compounds were also frequently detected, which likely reflects the natural grazing of the ewes. For some lowly abundant components, different absence/presence profiles were observed in different DF; however, highly abundant components were always found in all $3 \mathrm{DF}$, suggesting that the production site only generates minor differences in flavor, which is largely overruled by the much longer ripening process in Divle Cave. This is corroborated by the fact that our PCA analyses demonstrated clustering of raw milk samples from different DF was lost after curd production but retained in the final cheeses. The concentrations of many volatile compounds were significantly changed during the ripening period in the same production. These variations indicated that a variable cheese medium and dynamic conditions were available in the structure of cheese. These minor differences are also derived from some standardization problems during traditional production techniques. This paper presents data for determining the authentication of this traditional cheese and can be useful for comparative 
purposes in future studies both on mold ripened and raw ewe milk cheeses.

\section{ACKNOWLEDGMENTS}

This work was financially supported by Scientific Research Projects Unit of Ankara University, Turkey, and the Islamic Development Bank (Jeddah, Kingdom of Saudi Arabia) Merit PhD-Scholarship Programme for High Technology. We also thank the Governorship of Ayranc1 District (Turkey) for their help providing the cheeses.

\section{REFERENCES}

Agrawal, R., and R. Joseph. 2000. Bioconversion of alpha pinene to verbenone by resting cells of Aspergillus niger. Appl. Microbiol. Biotechnol. 53:335-337.

AOAC International. 1995. Official Methods of Analysis, vol. II., 16th ed. AOAC International, Arlington, VA.

Ardo, Y., and A. Polychroniadou. 1999. Laboratory Manual for Chemical Analysis of Cheese. Office for Official Publications of the European Communities, Luxembourg.

Barron, L. J. R., Y. Redondo, M. Aramburu, P. Gil, F. J. Pérez-Elortondo, M. Albisu, A. I. Nájera, M. de Renobales, and E. Fernández-García. 2007. Volatile composition and sensory properties of industrially produced Idiazabal cheese. Int. Dairy J. 17:1401-1414.

Barron, L. J. R., Y. Redondo, C. E. Flanagan, F. J. Pérez-Elortondo, M. Albisu, A. I. Nájera, M. de Renobales, and E. Fernández-Garcí. 2005. Comparison of the volatile composition and sensory characteristics of Spanish PDO cheeses manufactured from ewes' raw milk and animal rennet. Int. Dairy J. 15:371-382.

Bergamini, C. V., I. V. Wolf, M. C. Perotti, and C. A. Zalazar. 2010. Characterisation of biochemical changes during ripening in Argentinean sheep cheeses. Small Rumin. Res. 94:79-89.

Bintsis, T., and R. K. Robinson. 2004. A study of the effects of adjunct cultures on the aroma compounds of Feta-type cheese. Food Chem. $88: 435-441$.

Bontinis, T. G., H. Mallatou, E. C. Pappa, T. Massouras, and E. Alichanidis. 2012. Study of proteolysis, lipolysis and volatile profile of a traditional Greek goat cheese (Xinotyri) during ripening. Small Rumin. Res. 105:193-201.

Borge, G. I. A., E. Sandberg, J. Øyaas, and R. K. Abrahamsen. 2016. Variation of terpenes in milk and cultured cream from Norwegian alpine rangeland-fed and in-door fed cows. Food Chem. 199:195202.

Carbonell, M., M. Nunez, and E. Fernandez-Garcia. 2002. Evolution of the volatile components of ewe raw milk La Serena cheese during ripening. Correlation with flavour characteristics. Lait 82:683-698

Centeno, J. A., F. J. Tomillo, E. Fernández-García, P. Gaya, and M. Nuñez. 2002. Effect of wild strains of Lactococcus lactis on the volatile profile and the sensory characteristics of ewes' raw milk cheese. J. Dairy Sci. 85:3164-3172.

Chávez, R., A. Roa, K. Navarrete, J. Trebotich, Y. Espinosa, and I. Vaca. 2010. Evaluation of properties of several cheese-ripening fungi for potential biotechnological applications. Mycoscience $51: 84-87$.

Collins, Y. F., P. L. H. McSweeney, and M. G. Wilkinson. 2003. Lipolysis and free fatty acid catabolism in cheese: A review of current knowledge. Int. Dairy J. 13:841-866.

Curioni, P. M. G., and J. O. Bosset. 2002. Key odorants in various cheese types as determined by gas chromatography-olfactometry. Int. Dairy J. 12:959-984.

Delgado, F. J., J. González-Crespo, R. Cava, J. García-Parra, and R. Ramírez. 2010. Characterisation by SPME-GC-MS of the volatile profile of a Spanish soft cheese P.D.O. Torta del Casar during ripening. Food Chem. 118:182-189.
Delgado, F. J., J. Gonzalez-Crespo, R. Cava, and R. Ramirez. 2011 Formation of the aroma of a raw goat milk cheese during maturation analysed by SPME-GC-MS. Food Chem. 129:1156-1163.

Di Cagno, R., J. Banks, L. Sheehan, P. F. Fox, E. Y. Brechany, A. Corsetti, and M. Gobbetti. 2003. Comparison of the microbiological, compositional, biochemical, volatile profile and sensory characteristics of three Italian PDO ewes' milk cheeses. Int. Dairy J. 13:961-972.

Engels, W. J. M., R. Dekker, C. de Jong, R. Neeter, and S. Visser 1997. A comparative study of volatile compounds in the watersoluble fraction of various types of ripened cheese. Int. Dairy J. 7:255-263.

Fernández-García, E., M. Carbonell, P. Gaya, and M. Nuñez. 2004 Evolution of the volatile components of ewes raw milk Zamorano cheese. Seasonal variation. Int. Dairy J. 14:701-711.

Gallois, A., and D. Langlois. 1990. New results in the volatile odorous compounds of French cheeses. Lait 70:89-106.

Gómez-Ruiz, J. A., C. Ballesteros, M. A. G. Viñas, L. Cabezas, and I. Martínez-Castro. 2002. Relationships between volatile compounds and odour in Manchego cheese: comparison between artisanal and industrial cheeses at different ripening times. Lait 82:613-628.

Guinee, T. P. 2004. Salting and the role of salt in cheese. Int. J. Dairy Technol. 57:99-109.

Hayaloglu, A. A., E. Y. Brechany, K. C. Deegan, and P. L. H. McSweeney. 2008. Characterization of the chemistry, biochemistry and volatile profile of Kuflu cheese, a mould-ripened variety. LWTFood Sci. Technol. 41:1323-1334.

Hayaloglu, A. A., S. Cakmakci, E. Y. Brechany, K. C. Deegan, and P. L. H. McSweeney. 2007a. Microbiology, biochemistry, and volatile composition of Tulum cheese ripened in goat's skin or plastic bags. J. Dairy Sci. 90:1102-1121.

Hayaloglu, A. A., P. F. Fox, M. Guven, and S. Cakmakci. 2007b. Cheeses of turkey: 1. Varieties ripened in goat-skin bags. Lait 87:79-95.

Hayaloglu, A. A., and I. Karabulut. 2013. SPME/GC-MS characterization and comparison of volatiles of eleven varieties of Turkish cheeses. Int. J. Food Prop. 16:1630-1653.

IDF. 1982. Cheese and processed cheese-Total solid content. Standard no. 4A. International Dairy Federation, Brussels, Belgium.

IDF. 1988. Cheese and cheese products- Determination of chloride content. Pantetiometric titration method. Standard no. 88A. International Dairy Federation, Brussels, Belgium.

IDF. 1993. Milk determination of nitrogen content. Standard no. 20B. International Dairy Federation, Brussels, Belgium.

Lee, J. H., R. Diono, G. Y. Kim, and D. B. Min. 2003. Optimization of solid phase microextraction analysis for the headspace volatile compounds of Parmesan cheese. J. Agric. Food Chem. 51:11361140

Martin, N., C. Berger, C. Le Du, and H. E. Spinnler. 2001. Aroma compound production in cheese curd by coculturing with selected yeast and bacteria. J. Dairy Sci. 84:2125-2135.

Massouras, T., E. C. Pappa, and H. Mallatou. 2006. Headspace analysis of volatile flavour compounds of Teleme cheese made from sheep and goat milk. Int. J. Dairy Technol. 59:250-256.

McSweeney, P. L. H. 2004. Biochemistry of cheese ripening. Int. J. Dairy Technol. 57:127-144.

McSweeney, P. L. H., and M. J. Sousa. 2000. Biochemical pathways for the production of flavour compounds in cheeses during ripening: A review. Lait 80:293-324.

Molimard, P., and H. E. Spinnler. 1996. Review: Compounds involved in the flavor of surface mold-ripened cheeses: Origins and properties. J. Dairy Sci. 79:169-184.

Munoz, N., M. Ortigosa, P. Torre, and J. M. Izco. 2003. Free amino acids and volatile compounds in an ewe's milk cheese as affected by seasonal and cheese-making plant variations. Food Chem. $83: 329-338$

Ozturkoglu-Budak, S., M. J. Figge, J. Houbraken, and R. P. de Vries, 2015. The diversity and evolution of microbiota in traditional Turkish Divle Cave cheese during ripening. Int. Dairy J. http:// dx.doi.org/10.1016/j.idairyj.2015.09.011. 
Pappa, E. C., T. Massouras, K. Sotirakoglou, and I. Kandarakis. 2013. Formation of volatile compounds in Teleme cheese manufactured with mesophilic and thermophilic dairy starters. Small Rumin. Res. 111:110-119.

Poulopoulou, I., E. Zoidis, T. Massouras, and I. Hadjigeorgiou. 2012. Terpenes transfer to milk and cheese after oral administration to sheep fed indoors. J. Anim. Physiol. Anim. Nutr. (Berl.) 96:172181.

Poveda, J. M., and L. Cabezas. 2006. Free fatty acid composition of regionally-produced Spanish goat cheese and relationship with sensory characteristics. Food Chem. 95:307-311.

Revello Chion, A., E. Tabacco, D. Giaccone, P. G. Peiretti, G. Battelli, and G. Borreani. 2010. Variation of fatty acid and terpene profiles in mountain milk and "Toma piemontese" cheese as affected by diet composition in different seasons. Food Chem. 121:393-399.

Rothe, M., C. Kornelson, and R. Schrodter. 1994. Key components of food flavour-A sensory study on Blue cheese flavor Pages 221-232 in Trends in Flavour Research. Vol. 35. H. Maarse and D. G. Van der Heij, ed., Zeist, the Netherlands.

Sablé, S., and G. Cottenceau. 1999. Current knowledge of soft cheeses flavor and related compounds. J. Agric. Food Chem. 47:4825-4836.

Schlesser, J. E., S. J. Schmidt, and R. Speckman. 1992. Characterization of chemical and physical changes in Camembert cheese during ripening. J. Dairy Sci. 75:1753-1760.
Settanni, L., and G. Moschetti. 2010. Non-starter lactic acid bacteria used to improve cheese quality and provide health benefits. Food Microbiol. 27:691-697.

Smit, G., B. A. Smit, and W. J. M. Engels. 2005. Flavour formation by lactic acid bacteria and biochemical flavour profiling of cheese products. FEMS Microbiol. Rev. 29:591-610.

Tavaria, F. K., A. C. Silva Ferreira, and F. X. Malcata. 2004. Volatile free fatty acids as ripening indicators for Serra da Estrela cheese. J. Dairy Sci. 87:4064-4072.

Viallon, C., B. Martin, I. Verdier-Metz, P. Pradel, J. P. Garel, and J. B. Coulon. 2000. Transfer of monoterpenes and sesquiterpenes from forages into milk fat. Lait 80:635-641.

Visser, S. 1993. Proteolytic enzymes and their relation to cheese ripening and flavor: An overview. J. Dairy Sci. 76:329-350.

Wolf, I. V., M. C. Perotti, S. M. Bernal, and C. A. Zalazar. 2010 Study of the chemical composition, proteolysis, lipolysis and volatile compounds profile of commercial Reggianito Argentino cheese: Characterization of Reggianito Argentino cheese. Food Res. Int. 43:1204-1211.

Yvon, M., and L. Rijnen. 2001. Cheese flavour formation by amino acid catabolism. Int. Dairy J. 11:185-201. 